Психология. Журнал Высшей школы экономики,

2018. T. 15. № 3. C. 464-476. DOI: 10.17323/1813-8918-2018-3-464-476

\title{
РАЗРАБОТКА ОПРОСНИКА ДЛЯ ИЗУЧЕНИЯ АТТИТЮДОВ К ВОЙНЕ КАК К СПОСОБУ РАЗРЕШЕНИЯ МЕЖДУНАРОДНЫХ КОНФЛИКТОВ
}

\author{
A.H. HEBPЮEB \\ аГОБУ В'О Финансовый упиверситет при Правительстве Российской Федерспии, 125993, ГСП-3, \\ Москва, Ленинградский просп., 49
}

\begin{abstract}
Резюме
В статье описана авторская методика для изучения аттитюдов к войне как к способу решения международных конфликтов. Ее создание происходило в два основных этапа. На первом этапе был сформулирован ряд утверждений, которые отражали восприятие различных аспектов войны. Затем были отобраны те, которые вошли в окончательный вариант опросника. Разработанная методика включала в себя 6 факторов (эффективность войны, моральная оправданность войны, экономические последствия войны, социальные последствия войны, позитивные гуманитарные последствия войны, негативные гуманитарные последствия войны), которые образуют единый фактор общих аттитюдов к войне. В исследовании $1(\mathrm{~N}=978)$ результаты проведенного конфирматорного факторного анализа показали, что вариант опросника, который включает в себя 12 утверждений, демонстрирует приемлемый уровень соответствия эмпирическим данным. Мультигрупповой анализ продемонстрировал структурную эквивалентность при использовании этого опросника на двух группах: 1) мужчин и женщин, 2) людях младше и старше 30 лет. При этом выяснилось, что мужчины обладают более позитивными аттитюдами к войне, чем женщины, а люди до 30 лет - более позитивными аттитюдами, чем люди старше 30 лет. Затем в исследовании $2(\mathrm{~N}=1492)$ была проанализирована внешняя валидность методики. Была установлена позитивная связь аттитюдов к войне с уровнем правого авторитаризма и ориентацией на социальное доминирование в области международных отношений. В данном исследовании показатель надежности опросника для изучения аттитюдов к войне демонстрировал высокое значение $(\alpha=0.87)$.
\end{abstract}

Ключевые слова: аттитюды к войне, правый авторитаризм, ориентация на социальное доминирование, национализм, методика.

Международные конфликты происходят на протяжении всей истории человечества и часто приводят к серьезным гуманитарным, экономическим и политическим последствиям. Для разрешения этих конфликтов люди используют различные методы от мирных переговоров до военных действий. Однако 
во многих случаях военные действия привлекают большее внимание и считаются более важным событием, чем мирное разрешение проблем.

В частности, опросы общественного мнения показывают, что к числу наиболее важных событий 1994 и 1995 гг. российские граждане относили войну в Чечне, 1999 г. - войну в Югославии, 2003 г. - войну в Ираке, 2008 г. - войну в Южной Осетии (Общественное мнение - 2009, 2009, с. 11-17), а 2017 г. войну в Сирии (Левада-центр, 2018). Интерес к военным действиям сопровождается определенным - позитивным или негативным - отношением к ним.

Первые исследования, посвященные аттитюдам к войне, были проведены около 80 лет назад - во время Второй мировой войны. Однако интенсивное изучение этих аттитюдов началось только в конце XX в. С тех пор подобные исследования проводятся в разных странах мира, в том числе в США, Израиле, Австралии, Великобритании. Для измерения аттитюдов к войне психологи используют опросники. Эти методики можно разделить на две группы.

В одних исследованиях рассматриваются аттитюды к конкретным военным действиям, например войне в Ираке, Сирии и т.д. (например: Heskin, Power, 1994; Doty et al., 1997; Duncan, Stewart, 1995). В других случаях анализируются аттитюды к войне вообще (Weise et al., 2008; Bizumic et al., 2013; Jones-Wiley et al., 2007). Опросники для измерения аттитюдов к конкретным военным кампаниям имеют культурную и временну́ю специфику, но используются гораздо чаще, чем опросники для измерения аттитюдов к войне как к способу разрешения военных конфликтов.

Наиболее популярной методикой для измерения общих аттитюдов к войне является опросник, предложенный Л. Нельсоном (короткая версия - Nelson, 1995, расширенная версия - Nelson, Milburn, 1999). Он включает в себя прямые (отражающие позитивные аттитюды) и обратные (отражающие негативные аттитюды) утверждения, с которыми участники исследования могут согласиться или не согласиться. Однако пункты этого опросника обладают культурной спецификой.

Целью данного исследования стало создание русскоязычной методики для измерения обших аттитюдов к войне. В ходе исследования были сформулированы утверждения, проанализирована структурная и внешняя валидность методики. Для проверки внешней валидности были использованы три психологические характеристики, выбранные на основании предыдущих исследований: правый авторитаризм, ориентация на социальное доминирование и национализм.

Многочисленные психологические исследования показали, что аттитюды к конкретным военным кампаниям - войне во Вьетнаме (Izzett, 1971), Персидском заливе (Doty et al., 1997; Duncan, Stewart, 1995), Ираке (Cohrs et al., 2005; Crowson et al., 2005, 2006; McFarland, 2005), Югославии (Cohrs, Moschner, 2002), использованию военной силы в Прибалтийских странах (McFarland et al., 1992) - позитивно связаны с правым авторитаризмом (некритическим позитивным отношением к существующим в обществе политическим 
лидерам и распространенным социальным нормам). Как следствие, в исследовании было выдвинуто предположение о том, что аттитюды к войне как к способу разрешения международных конфликтов будут позитивно связаны с правым авторитаризмом.

Кроме того, некоторые исследования продемонстрировали, что аттитюды к конкретным военным кампаниям, в частности к войне в Ираке (Cohrs et al., 2005; Crowson et al., 2006; Heaven et al., 2006), позитивно связаны с ориентацией на социальное доминирование внутри общества (одобрение существующей в обществе социальной иерархии, неприятие идеи группового равенства). Однако эта связь была обнаружена не во всех исследованиях (Crowson, 2009b).

Возможно, это происходит, поскольку ориентация на социальное доминирование отражает отношение к иерархии между группами, сосуществующими в одной стране, тогда как в современном мире войны часто являются средством решения проблем, возникаюших между разными странами. В данном исследовании было выдвинуто предположение, что аттитюды к войне как к способу разрешения международных конфликтов будут позитивно связаны с ориентацией на социальное доминирование в международных отношениях.

И наконец, предыдущие исследования показали, что аттитюды к отдельным военным кампаниям, например войне в Ираке (Federico et al., 2005) и войне против стран, представляющих террористическую угрозу (Crowson, 2009a), позитивно связаны с национализмом - признанием превосходства своей страны над другими странами, поэтому было выдвинуто предположение о том, что аттитюды к войне как к способу разрешения международных конфликтов будут позитивно связаны с национализмом.

Создание методики состояло из двух этапов. На первом этапе был сформулирован пул утверждений, отражающих восприятие различных аспектов войны; после чего были отобраны утверждения, которые вошли в окончательный вариант опросника. На втором этапе была проанализирована факторная структура, надежность, структурная и внешняя валидность методики.

\section{Исследование 1}

Выборка. Исследование было проведено с ноября по декабрь 2014 г. В нем приняли участие 978 респондентов (499 мужчин и 479 женщин), средний возраст - 42.9 года $(\mathrm{SD}=12.87)$. Респонденты заполняли методики на добровольной основе, без специального вознаграждения.

Методики. Перед началом исследования были проанализированы обсуждения, посвященные военным действиям, которые происходили на русскоязычных форумах и в социальных сетях. В ходе этого анализа были выделены пять основных тем, которые затрагивались участниками: эффективность войны, моральная оправданность войны, а также гуманитарные, социальные и әкономические последствия военных действий. В результате были сформулированы 15 прямых и 18 обратных утверждений, отражающих аттитюды к различным аспектам войны. 
Эти утверждения были размещены в форме опросника на сайте Google Docs. B различных социальных сетях были помещены сообщения администраторам групп, в котором содержалась просьба оставить на стене группы объявление о проведении исследования. Тематика групп, в которых было размещено объявление об исследовании, была связана в основном с политикой, войной, экономикой, военными действиями и т.д. (к примеру, в исследовании участвовали члены групп: «Мне реально нравится Путин! [Политика, Россия]», «Коротко о Главном | Политика»). Респонденты должны были выразить степень своего согласия с этими утверждениями по семибалльной шкале: 1 - «Совершенно не согласен», 7 - «Совершенно согласен».

\section{Результать}

Анализ результатов состоял из двух стадий. Сначала был проведен эксплораторный факторный анализ, на основе которого были выделены утверждения, вошедшие в окончательный вариант методики. Затем был проведен конфирматорный факторный анализ, который продемонстрировал структурную валидность опросника.

Эксплораторный факторный анализ был проведен с помощью Mplus 7.4. Он продемонстрировал, что утверждения образовали шесть основных факторов. Для дальнейшего анализа были выбраны 12 утверждений, отражающих различные аспекты аттитюдов к войне. При выборе утверждений учитывалась нагрузка утверждения на соответствующий фактор и на другие факторы. В окончательный вариант методики вошли утверждения с относительно высокой нагрузкой на соответствующий фактор и относительно низкой нагрузкой на другие факторы.

Конфирматорный факторный анализ был проведен с помощью программы Mplus 7.4. В ходе него проверялась модель, которая включала в себя шесть первичных и один вторичный фактор (см. рисунок 1). Она продемонстрировала удовлетворительный уровень соответствия данным $\left(\chi^{2}=272.066, \mathrm{df}=48\right.$, $p<0.01, \mathrm{CFI}=0.953, \mathrm{TLI}=0.936, \mathrm{RMSEA}=0.069, \mathrm{SRMR}=0.039, \mathrm{AIC}=$ $=42258.110, \mathrm{BIC}=42329.301)$. Этот вариант методики был рассмотрен на втором этапе исследования.

\section{Исследование 2}

Выборка. Исследование было проведено на двух подвыборках в разное время: на первой подвыборке в июне 2015 г., на второй подвыборке в ноябредекабре 2015 г. В нем приняли участие 1492 человека, входящих в состав двух подвыборок. В первой подвыборке было 897 человек (462 мужчины и 435 женщин), средний возраст - 46.2 года $(\mathrm{SD}=12.3)$. Во второй подвыборке было 595 человек (340 мужчин, 255 женщин), средний возраст - 29.7 года (SD = $=10.5)$. Респонденты заполняли методики на добровольной основе, без специального вознаграждения. 


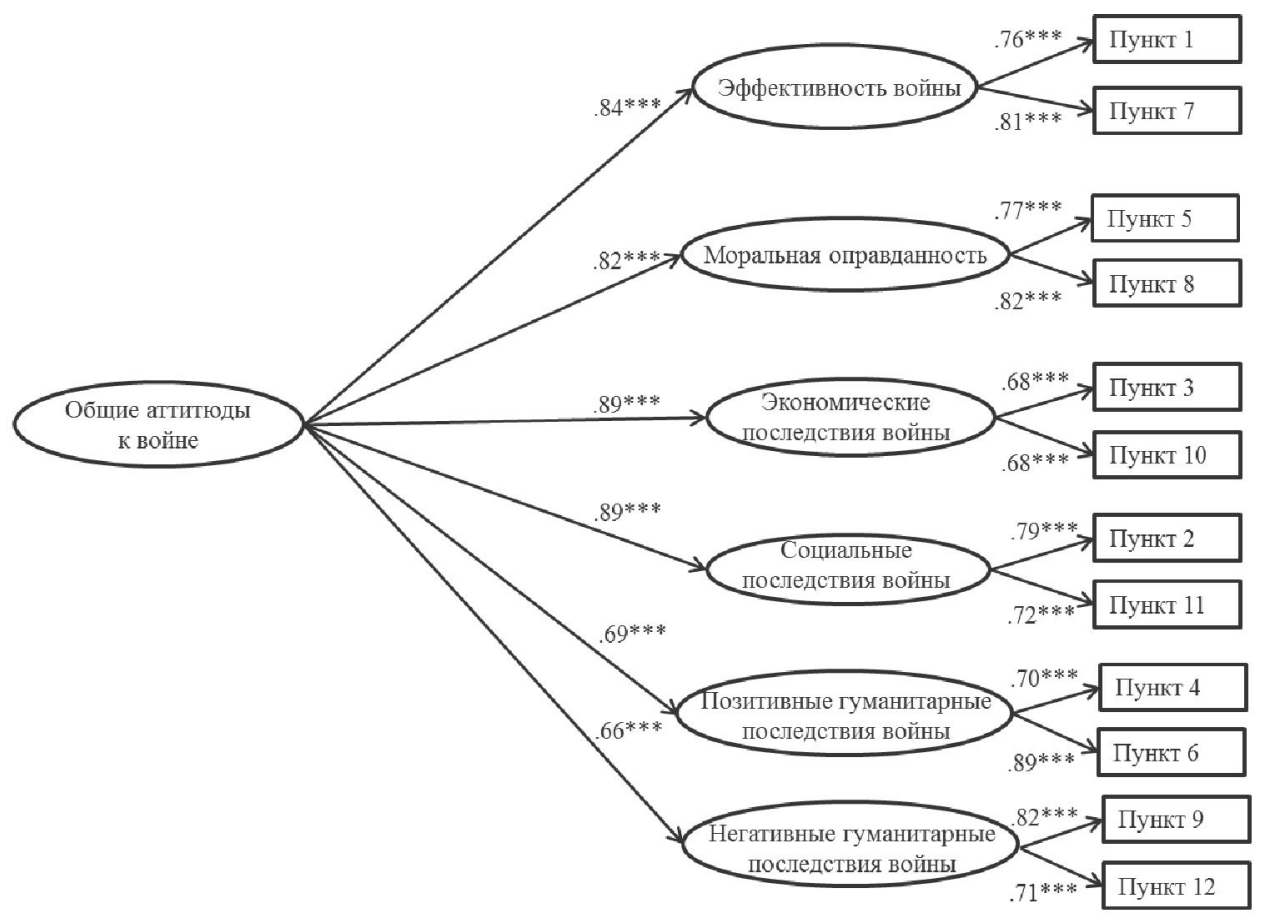

Методики. Участники заполняли опросник для измерения аттитюдов к войне, а также три методики для измерения внешней валидности опросника.

Aттитюды к войне. Для измерения отношения к войне как к способу разрешения международных конфликтов были использованы 12 утверждений, выделенных на предыдущей стадии исследования. Они касались эффективности и моральной оправданности войны, а также экономических, социальных и гуманитарных последствий военных действий. Респонденты должны были оценить степень своего согласия с каждым утверждением по 7-балльной шкале: от 1 - «Совершенно не согласен» до 7 - «Совершенно согласен» (см. приложение 1).

Правый авторитаризм. Для измерения правого авторитаризма был использован опросник Б. Альтмейера (Altemeyer, 1988) в адаптации Дьяконовой $(2001)$. Он включалІ в себя 30 утверждений $\left(\alpha_{\text {данное исследование }}=0.90\right)$. Респонденты должны были оценить степень согласия с каждым утверждением по девятибалльной шкале: 1 - «Полностью не согласен», 9 - «Полностью согласен».

Ориентация на сочиальное доминирование в международных отноиения. Для измерения ориентации на социальное доминирование использовался опросник, предложенный Дж. Сиданиусом и Ф. Пратто (Pratto et al., 1994), 
модифицированный для изучения отношения к иерархии в международных отношениях (Гулевич и др., 2018). Он включал в себя 10 утверждений $\left(\alpha_{\text {данне ислелование }}=0.85\right)$. Респонденты должны были оценить степень согласия с каждым утверждением по семибалльной шкале: 1 - «Совершенно не согласен», 7 - «Совершенно согласен»

Национализм. Для измерения национализма использовались четыре утверждения, которые были заимствованы из международного социального опроса (Григорян, Лепшокова, 2012): «Я скорее предпочту быть гражданином России, чем любой другой страны», «Мир был бы намного лучше, если бы люди из других стран были больше похожи на россиян», «Говоря в целом, Россия лучше, чем большинство других стран», «Жители России должны поддерживать свою страну, несмотря на ее неправоту». Респонденты должны были указать степень согласия с ними по пятибалльной шкале: 1 «Совершенно не согласен», 5 - «Совершенно согласен».

Данные были получены с помощью электронного варианта опросника. Онлайн-версия опросника была создана на сайте https:/virtualexs.ru/. Ссылки на опросник были размешены на интернет-сайтах: voxru.net, subscribe.ru. Респонденты принимали участие в данном исследовании на добровольной основе. Первой подвыборке предъявлялись опросники для измерения аттитюдов к войне, правого авторитаризма и ориентации на социальное доминирование в международных отношениях, а второй подвыборке - опросники для измерения аттитюдов к войне и национализма.

\section{Результатьь}

Для анализа факторной структуры опросника был использован конфирматорный факторный анализ. Он показал, что методика демонстрирует удовлетворительный уровень соответствия данным $\left(\chi^{2}=225.219, \mathrm{df}=47, p<0.01\right.$, $\mathrm{CFI}=0.967, \mathrm{TLI}=0.954, \mathrm{RMSEA}=0.050, \mathrm{SRMR}=0.028, \mathrm{AIC}=60269.707$, $\mathrm{BIC}=60497.975)$.

Для анализа надежности опросника был использован коэффициент $\alpha$ Кронбаха. Он продемонстрировал, что шкала имеет высокий уровень согласованности $(\alpha=0.87)$.

Для анализа структурной валидности был использован мультигрупповой факторный анализ. Для этого выборка была сначала разделена на мужчин $(\mathrm{N}=802)$ и женщин $(\mathrm{N}=690)$, а затем на людей до 30 лет включительно $(\mathrm{N}=507)$ и старше 31 года $(\mathrm{N}=984)$. Он показал, что в обоих случаях опросник обладает конфигурационной, метрической и скалярной инвариантностью (см. таблицу 1).

В целом участники продемонстрировали средний уровень аттитюдов к войне $(\mathrm{M}=2.81, \mathrm{SD}=0.91 ; t=-50.10, p=0.000)$. Однако сравнение средних значений с помощью $\mathrm{t}$-критерия показало, что мужчины $(\mathrm{M}=2.92, \mathrm{SD}=0.93)$ имеют более позитивные аттитюды к войне, чем женшины $(\mathrm{M}=2.68, \mathrm{SD}=.86)$ $(\mathrm{t}=4.15, p=0.000)$. Кроме того, респонденты в возрасте до 30 лет $(\mathrm{M}=2.94$, 
Результаты мультигруппового факторного анализа

\begin{tabular}{|c|c|c|c|c|c|c|c|c|c|c|c|}
\hline Группы & Модель & $x^{2}$ & df & $\begin{array}{l}\text { RMSEA } \\
{[90 \% \text { CI] }}\end{array}$ & SRMR & CFI & TLI & $\mathrm{AIC}$ & $\Delta \chi^{2}$ & $\Delta \mathbf{d f}$ & $\triangle \mathrm{CFI}$ \\
\hline \multirow{3}{*}{$\begin{array}{l}\text { Гендерные } \\
\text { группы } \\
\text { (мужчины, } \\
\text { женщины) }\end{array}$} & $\begin{array}{l}\text { Конфигурационная } \\
\text { инвариантность }\end{array}$ & $166.076^{*}$ & 78 & $.039[.031 ; .047]$ & .026 & .977 & .961 & 60041 & - & - & - \\
\hline & $\begin{array}{l}\text { Метрическая } \\
\text { инвариантность }\end{array}$ & $172.966^{*}$ & 84 & $.038[.030 ; .046]$ & .026 & .976 & .963 & 60035 & 6.89 & 6 & .001 \\
\hline & $\begin{array}{l}\text { Скалярная } \\
\text { инвариантность }\end{array}$ & $192.296^{*}$ & 90 & $.039[.031 ; .047]$ & .029 & .973 & .960 & 60044 & $19.33^{* *}$ & 6 & .003 \\
\hline \multirow{3}{*}{$\begin{array}{c}\text { Возрастные } \\
\text { группы } \\
\text { (до } 30 \text { лет, от } \\
31 \text { и старше) }\end{array}$} & $\begin{array}{l}\text { Конфигурационная } \\
\text { инвариантность }\end{array}$ & $127.687^{*}$ & 78 & $.029[.019 ; .038]$ & .021 & .987 & .979 & & - & - & - \\
\hline & $\begin{array}{l}\text { Метрическая } \\
\text { инвариантность }\end{array}$ & $136.037^{*}$ & 84 & $.029[.020 ; .037]$ & .024 & .986 & .978 & 59873 & 8.35 & 6 & .001 \\
\hline & $\begin{array}{l}\text { Скалярная } \\
\text { инвариантность }\end{array}$ & $164.908^{*}$ & 90 & $.033[.025 ; .041]$ & .028 & .980 & .971 & 59895 & $28.87 * * *$ & 6 & .006 \\
\hline
\end{tabular}

${ }^{*} p<0.05,{ }^{* *} p<0.01,{ }^{* * *} p<0.001$. 
$\mathrm{SD}=1.00)$ демонстрируют более позитивные аттитюды к войне, чем люди в возрасте старше 30 лет $(\mathrm{M}=2.74, \mathrm{SD}=0.85)(\mathrm{t}=5.15, p=0.000)$.

Для определения внешней валидности опросника был проведен корреляционный анализ. Результаты, полученные на первой подвыборке, показали, что аттитюды к войне как к способу разрешения международных конфликтов позитивно связаны с правым авторитаризмом $(r=0.16, p=0.000)$ и с ориентацией на социальное доминирование в международных отношениях $(r=0.44$ $p=0.000$ ). В то же время результаты, полученные на второй подвыборке, продемонстрировали, что связь между аттитюдами к войне как к способу разрешения международных конфликтов и национализмом не достигла уровня статистической значимости $(r=-0.04, p=0.386)$.

\section{Обсуждение результатов}

В данном исследовании была проанализирована методика для измерения аттитюдов к войне как к способу разрешения международных конфликтов. Эта методика включает в себя ряд утверждений, отражающих разные аспекты восприятия войны: оценку эффективности и моральной оправданности, а также экономических, социальных и гуманитарных последствий военных действий. Исследование продемонстрировало надежность-согласованность и структурную валидность методики.

Однако было обнаружено, что мужчины выражают более позитивное отношение к войне, чем женщины. Эти результаты согласуются с данными других исследований (например: Van der Linden et al., 2017). По мнению ряда ученых, это происходит, поскольку гендерные стереотипы, распространенные во многих обществах, предъявляют к женщинам и мужчинам разные требования. От женщин ожидают терпимости и способности идти на компромисс (Maoz, 2012). В результате женщины демонстрируют более высокий уровень эмпатии (Brooks, Valentino, 2011) и ориентации на сохранение дружественных отношений между членами группы (Tessler et al., 1999), чем мужчины. Эти особенности отражаются на аттитюдах к войне.

Кроме того, полученные результаты показали, что люди старше 30 лет выражают более негативное отношение к военным действиям, чем более молодые люди. Эти результаты согласуются с данными других исследований, которые показали, что с возрастом уровень агрессивности снижается (Stoner, Spencer, 1987). Возможно, это происходит, поскольку люди более старшего возраста имеют достаточный жизненный опыт, чтобы использовать его для решения возникающих разногласий мирным путем. Эти особенности также связаны с идеей решать конфликты в международной сфере мирными, а не военными способами.

Кроме того, исследование показало, что методика обладает внешней валидностью. Однако аттитюды к войне как к способу разрешения международных конфликтов сильнее связаны с ориентацией на социальное доминирование в международных отношениях, чем с правым авторитаризмом. 
Возможно, это обусловлено тем, что правый авторитаризм описывает безусловное позитивное отношение человека к социальным нормам и готовность следовать за политическими лидерами. Как следствие, люди с высоким уровнем правого авторитаризма выражают более позитивное отношение к войне, только если считают, что социальные нормы и политические лидеры одобряют такие действия.

В то же время ориентация на социальное доминирование в международных отношениях описывает отношение к иерархии между странами, в которой одни государства смогли занять более высокое место, чем другие. Поскольку военные действия позволяют стране получить или подтвердить свое превосходство над другими государствами, люди, которые одобряют международную иерархию, одновременно одобряют и военные действия.

Однако вопреки ожиданиям выяснилось, что аттитюды к войне как к способу разрешения международных конфликтов не связаны с уровнем национализма. Эти результаты соответствуют данным, полученным в недавнем исследовании, показавшем, что национализм связан с позитивным отношением к вмешательству в дела других стран преимущественно в случае возникновения реальной или мнимой угрозы с их стороны (Feinstein, 2016). Однако этот вопрос требует дополнительного исследования.

\section{Литература}

Григорян, Л. К., Лепшокова, 3. Х. (2012). Эмпирическая модель взаимосвязи гражданской идентичности и установок по отношению к иммигрантам с экономическими представлениями россиян. Социальная психология и общество, 2, 5-20.

Гулевич, О. А., Агадуллина, Е. Р., Хухлаев, О. Е. (2018). Одобрение групповой иерархии: русскоязычная версия шкалы для измерения ориентации на социальное доминирование. Психология. Журнал Высией икколы экономики, 15(3), 407-426.

Дьяконова, Н. А. (2001). Особенности авторитаризма и его взаимосвязь с ценностными ориентациями и локусом контроля у российских и американских студентов (Кандидатская диссертация). Режим доступа: http://dl1.lib.ua-ru.net/files/dfd/252/030359001.doc

Левада-центр. (2018, 1 февраля). Важнейиие события 2017 года. Режим доступа: https://www.levada.ru/2018/02/01/vazhnejshie-sobytiya-2017-goda/

Общественное мнение - 2009. (2009). М.: Левада-Центр. Режим доступа: http:/ www.levada.ru/ sites/default/files/levada_2009_rus.pdf

Ссылки на зарубежные источники см. в разделе References после англоязиного блока. 


\section{Опросник для измерения аттитюдов к войне как к способу разрешения} международных конфликтов

В современном мире войны используются для разрешения международных конфликтов. Подумайте о своем отношении к войне. Отметьте, в какой степени вы согласны с приведенными ниже утверждениями.

\begin{tabular}{|c|c|c|c|c|c|c|}
\hline 1 & 2 & 3 & 4 & 5 & 6 & 7 \\
\hline $\begin{array}{c}\text { Совершенно } \\
\text { не согласен }\end{array}$ & $\begin{array}{c}\text { Не } \\
\text { согласен }\end{array}$ & $\begin{array}{c}\text { Скорее не } \\
\text { согласен }\end{array}$ & $\begin{array}{c}\text { Не } \\
\text { уверен }\end{array}$ & $\begin{array}{c}\text { Скорее } \\
\text { согласен }\end{array}$ & Согласен & $\begin{array}{c}\text { Совершенно } \\
\text { согласен }\end{array}$ \\
\hline
\end{tabular}

1. Война - лучшее средство разрешения международных конфликтов.

2. Война позволяет защитить слабых, добиться соблюдения прав человека.

3. Война способствует прогрессу.

4. Война развивает в человеке лучшие качества.

5. Война - это демонстрация слабости, неспособности достичь своей цели иным путем.

6. Участие в военных действиях - это полезный опыт, который позволяет человеку лучше понять жизнь

7. Международные конфликты должны разрешаться путем переговоров, без использования оружия.

8. Войне нет оправданий.

9. Война пробуждает в человеке самые худшие качества.

10. Война способствует экономическому развитию стран-участников.

11. Война позволяет защитить людей, пострадавших от несправедливости.

12. Война делает людей циничными, лишает их веры в доброту и справедливость окружающего мира.

\section{Ключ:}

Эффективность войнь: $1,7^{*}$

Моральная оправданность войны: $5^{*}, 8^{*}$

Экономические последствия войны: 3,10

Социальные последствия войны: 2,11

Позитивные гуманитарные последствия войны: 4,6

Негативные гуманитарные последствия войны: 9*, 12*

* - обратные утверждения.

Неврюев Андрей Николаевич - старший преподаватель, кафедра «Управление персоналом и психология», ФГОБУ ВО Финансовый университет при Правительстве Российской Федерации.

Сфера научных интересов: социальная психология, политическая психология.

Контакты: a.n.nevruev@mail.ru, ANNevryuev@fa.ru 


\title{
Development of a Questionnaire to Measure Attitude to War as a Means of Solving International Conflicts
}

\author{
A.N. Nevryuev \\ ${ }^{a}$ Finance University under the Government of the Russian Federation (Moscow, Russia), 49, Leningradsky \\ avenue, Moscow, 125993, Russian Federation
}

\begin{abstract}
The article describes the authors' tool to measure attitudes towards war as a means to solve international conflicts. Its construction passed two main steps. On the first step a number of items were formulated, which reflected the perception of various aspects of war. Then those items were chosen that constituted the final version of the questionnaire. The developed questionnaire comprised 6 factors (effectiveness of war, moral justification of war, economic aftermath of war, social aftermath of war, positive humanitarian aftermath of war, negative humanitarian aftermath of war), which add into a unified factor of general attitudes towards war. In the Study $1(\mathrm{~N}=978)$ the results of confirmatory factor analysis showed that the version of the questionnaire that comprised 12 items demonstrated satisfactory fit to the empirical data. The multigroup analysis demonstrated structural equivalence with the use of the questionnaire in two samples: 1) man and women; 2) people older and younger than 30 years. It was found that men have more positive attitudes towards war, than women, and people younger than 30 bear more positive attitudes that those who are older than 30. Positive links of attitudes towards war with the level of rightwing authoritarianism and orientation towards social dominance in the realm of international relationships were established. In the present study the alpha Cronbach's of the questionnaire of attitudes towards war was high $(\alpha=.87)$.
\end{abstract}

Keywords: attitude to war, right-wing authoritarianism, social dominance orientation, nationalism, questionnaire.

\section{References}

Altemeyer, B. (1998). The other "authoritarian personality." In M. P. Zanna (Ed.), Advances in experimental social.psychology (pp. 47-92). San Diego, CA: Academic Press.

Bizumic, B., Stubager, R., Mellon, S., Van der Linden, N., Iyer, R., \& Jones, B. M. (2013). (In)compatibility of attitudes toward peace and war. Political Psychology, 34, 673-693. doi:10.1111/pops.12032

Brooks, D. J., \& Valentino, B. A. (2011). A war of one's own: Understanding the gender gap in support for war. Public Opinion Quarterly, 75, 270-286. doi:10.1093/poq/nfr005

Cohrs, C., \& Moschner, B. (2002). Antiwar knowledge and generalized political attitudes as determinants of attitude toward the Kosovo War. Peace and Conflict: Joumal of Peace Psychology, 8, 139-155. doi:10.1207/S15327949PAC0802_03

Cohrs, J. C., Moschner, B., Maes, J., \& Kielmann, S. (2005). Personal values and attitudes toward war. Peace and Conflict:Joumal of Peace Psychology, 11, 293-312. doi:10.1207/s15327949pac1103_5 
Crowson, H. M. (2009a). Nationalism, internationalism, and perceived UN irrelevance: Mediators of relationships between authoritarianism and support for military aggression as part of the war on terror. Joumal of Applied Social Psychology, 39, 1137-1162. doi:10.1111/j.1559-1816.2009.00475.x

Crowson, H. M. (2009b). Right-wing authoritarianism and social dominance orientation: As mediators of worldview beliefs on attitudes related to the war on terror. Social Psychology, 40, 93103. doi:10.1027/1864-9335.40.2.93

Crowson, H. M., DeBacker, T. K., \& Thoma, S. J. (2005). Does authoritarianism predict post-9/11 attitudes? Personality and Individual Differences, 39, 1273-1283. doi:10.1016/j.paid.2005.06.005

Crowson, H. M., Debacker, T. K., \& Thoma, S. J. (2006). The role of authoritarianism, perceived threat, and need for closure or structure in predicting post-9/11 attitudes and beliefs. Joumal of Social Psychology, 146, 733-750. doi:10.3200/SOCP.146.6.733-750

Doty, R. M., Winter, D. G., Peterson, B. E., \& Kemmelmeier, M. (1997). Authoritarianism and American students' attitudes about the Gulf War, 1990-1996. Personality and Social Psychology Bulletin, 23, 1133-1143.

Duncan, L. E., \& Stewart, A. J. (1995). Still bringing the Vietnam War home: Sources of contemporary student activism. Personality and Social Psychology Bulletin, 21, 914-924.

Dyakonova, N. A. (2001). Osobennosti avtoritarizma i ego vzaimosvyaz's tsennostnymi onientatsiyami $i$ lokusom kontrolya u rossiiskikh $i$ amerikanskikh studentov [Specifics of authoritarianism and its interrelations with values orientations and locus of control in Russian and American students] (Ph.D. dissertation). Retrieved from http://dl1.lib.ua-ru.net/files/dfd/252/030359001.doc (in Russian)

Federico, C. M., Golec, A., \& Dial, J. L. (2005). The relationship between the need for closure and support for military action against Iraq: moderating effects of national attachment. Personality and Social Psychology Bulletin, 31, 621-632.

Feinstein, Y. (2016). Pulling the trigger: how threats to the nation increase support for military action via the generation of hubris. Sociological Science, 3, 317-334.

Grigoryan, L. K., \& Lepshokova, Z. Kh. (2012). Empiricheskaya model' vzaimosvyazi grazhdanskoi identichnosti i ustanovok po otnosheniyu $\mathrm{k}$ immigrantam s ekonomicheskimi predstavleniyami rossiyan [Empirical model of interrelation of civic identity and attitudes towards immigrants and economic beliefs of the Russians]. Sotsial'naya Psikhologiya i Obshchestro, 2, 5-20. (in Russian)

Gulevich, O. A., Agadullina, E. R., \& Khukhlaev, O. E. (2018). Approval of Group Hierarchy: Russian Version of Social Dominance Orientation Scale. Psychology. Joumal of the Higher School of Economics, 15(3), 407-428. (in Russian)

Heaven, P. C. L., Organ, L., Supavadeeprasit, S., \& Leeson, P. (2006). War and prejudice: A study of social values, right-wing authoritarianism, and social dominance orientation. Personality and Individual Differences, 40, 599-608.

Heskin, K., \& Power, V. (1994). The determinants of Australians' attitudes toward the Gulf War. The Joumal of Social Psychology, 134, 317-330.

Izzett, R. R. (1971). Authoritarianism and attitudes toward the Vietnam War as reflected in behavioral and self-report measures. Journal of Personality and Social Psychology, 17, 145-148. doi: $10.1037 / \mathrm{h} 0030391$

Jones-Wiley, D. G., Restori, A. F., Lee, H. B., Himelfarb, I., \& Boluyt, M. (2007). A psychometric evaluation of existing attitude measures toward capital punishment and war. North American Joumal of Psychology, 9, 475-484. 
Levada-Tsentr. (2018, 1 February). Vazhneishie sobytiya 2017 goda [The most important events of the year 2017]. Retrieved from https://www.levada.ru/2018/02/01/vazhnejshie-sobytiya-2017goda/ (in Russian)

Maoz, I. (2012). The women and peace hypothesis. In D. J. Christie (ed.), The encyclopedia of peace psychology (pp. 1185-1188). London: Wiley-Blackwell. doi:10.1002/9780470672532.wbepp296

McFarland, S. G. (2005). On the eve of war: authoritarianism, social dominance, and American students' attitudes toward attacking Iraq. Personality and Social Psychology Bulletin, 31, 360-67.

McFarland, S. G., Ageyev, V. S., \& Abalakina-Paap, M. A. (1992). Authoritarianism in the former Soviet Union. Journal of Personality and Social Psychology, 63, 1004-1010. doi:10.1037/00223514.63.6.1004

Nelson, L. L. (1995). Militaristic attitudes in college students: Developmental antecedents and personality correlates. Paper presented at the Annual Convention of the American Psychological Association, New York.

Nelson, L. L., \& Milburn, T. W. (1999). Relationships between problem-solving competencies and militaristic attitudes: Implications for peace education. Peace and Conflict: Joumal of Peace Psychology, 5, 149-168. doi:10.1207/s15327949pac0502_4

Obshchestvennoe mnenie - 2009. (2009). Moscow: Levada-Tsentr. Retrieved from http://www.levada.ru/sites/default/files/levada_2009_rus.pdf (in Russian)

Pratto, F., Sidanius, J., Stallworth, L. M., \& Malle, B. F. (1994). Social dominance orientation: A personality variable predicting social and political attitudes. Joumal of Personality and Social Psychology, 67, 741-763. doi:10.1037/0022-3514.67.4.741

Stoner, S. B., \& Spencer, W. B. (1987). Age and gender differences with the anger expression scale. Educational and Psychological Measurement, 47(2), 487-492. doi:10.1177/0013164487472023

Tessler, M., Nachtway, J., \& Grant, A. (1999). Further tests of the women and peace hypothesis: Evidence from cross-national survey research in the Middle East. Intemational Studies Quarterly, 43, 519-531.

Van der Linden, N., Leys, C., Klein, O., \& Bouchat, P. (2017). Are attitudes toward peace and war the two sides of the same coin? Evidence to the contrary from a French validation of the Attitudes Toward Peace and War Scale. PLoS ONE, 12(9), e0184001. doi:10.1371/journal.pone.0184001

Weise, D. R., Pyszczynski, T., Cox, C. R., Arndt, J., Greenberg, J., Solomon, S., \& Kosloff, S. (2008). Interpersonal politics: The role of terror management and attachment processes in shaping political preferences. Psychological Science, 19, 448-455. doi:10.1111/j.1467-9280.2008.02108.x

Andrey N. Nevryuev - senior lecturer, Department of HR Management and Psychology, Finance University under the Government of the Russian Federation.

Research area: social psychology, political psychology.

E-mail: a.n.nevruev@mail.ru, ANNevryuev@fa.ru 